\title{
To Study the Incidence of Electrical Contact Burns and To Evaluate the Pattern of Injury in a Tertiary Burn Care Centre
}

\author{
Pratap Duggirala', Sujata Sarabahi ${ }^{2}$, V. K. Tiwari ${ }^{3}$, Shiva Nagendra Reddy Annapareddy ${ }^{4}$ \\ ${ }^{1}$ Assistant Professor, Department of Burns, Plastic and Maxillofacial surgery, NRI Medical College \& Hospital, Chinakakani, Guntur, Andhra Pradesh, India, \\ ${ }^{2}$ Professor and Consultant, Department of Burns, Plastic and Maxillofacial surgery, Safdarjung Hospital, New Delhi, India, ${ }^{3}$ Professor \& HOD, Department \\ of Burns, Plastic and Maxillofacial surgery, RML Hospital, New Delhi, India, ${ }^{4}$ Assistant Professor, Department of Nephrology, NRI Medical College \& \\ Hospital, Chinakakani, Guntur, Andhra Pradesh, India.
}

\section{Abstract}

Background: Electrical burn is a unique form of trauma, in which mortality and morbidity are very high when compared to thermal burns. The effects of electrical current depend on the type of current, voltage, tissue resistance, the pathway and the duration. Aim: The aim of the current study is to find the incidence of electric burns and evaluate the pattern of injury in tertiary burn care centre. Subjects and Methods: It is a prospective observational study conducted in department of Burns, Plastic and Maxillofacial Surgery, Safdarjung Hospital, New Delhi over a period of one year. Results: Our study was done from first January 2011 to thirty first December 2011 in safdarjung hospital. Total number of patients treated for burns of all kinds during the same period is 5569. Among them total number of electrical burn incidence is 7.86\% (438). The age groups maximum affected are sixteen years to thirty years. Electric burns were more common from childhood up to forty years age group. In the present study, Out of total 438 patients males were 369 and females were 69 . This represented that $84.25 \%$ of the patients were male. Children constituted $18.5 \%$ (81) of all patients injured by electrical burns. In our study majority of the patients (266) had direct contact burns.125 patients had only flash burns and 47 patients had both contact and flash burns. Definite seasonal variation was observed with the highest number of patients in June to September months (48.6\%). In our study we found that there were 312 high voltage injuries and 126 low voltage injuries. We found that the major cause of electric injuries was while doing agriculture related work (rural areas) in fields etc. The present study revealed that, head injuries are the major associated injuries in Electrical burns. Conclusion: We conclude that to reduce the incidence of electrical burns local governments need to impart personalized education to the rural population regarding electrical burn injuries; simple passive measures like making use of local language and dialect for manufacturers' instructions and signboards; and the print and electronic media should be used effectively to impart necessary information.

Keywords: Electrical burns, High voltage, seasonal variation, Low voltage.

Corresponding Author: Dr. Pratap Duggirala, Assistant Professor, Department of Burns, Plastic and Maxillofacial surgery, NRI Medical College \& Hospital, Chinakakani, Guntur, Andhra Pradesh, India.

Received: December 2019

Accepted: December 2019

\section{Introduction}

In India we have a large number of health programs utilizing huge amounts of money and resources like pulse polio program etc, but we do not have any program for electrical burn injuries. The mortality and morbidity associated with electrical burn injuries is very high including loss of limbs or functional loss of limbs. The saddest part is that nearly all of these are preventable.

By collecting and analyzing the epidemiology of electric burns and the mortality and morbidity associated with it we can put pressure on the government to start programs for prevention of electric burns.

Electrical burn injuries represent a special type of lesion, in which disability is high and functional and aesthetic sequelae are significant. They occur less frequently than flame or liquid burns, and account for $3-4 \%{ }^{[1-5]}$ of all patients treated in burns centres. The damage due to electrical current is caused by two mechanisms - heating and the passage of electric current itself through tissues. Heating causes coagulative necrosis, and the passage of electrical current through tissues causes the disruption of cell membranes [6, 8]. The effects of electric current depend on the type of current, its voltage, the resistance of the tissues, the strength of the current, the pathway taken by the current through the body, the duration of contact, and individual susceptibility. The aim of the present study is to find the incidence of electric burns and evaluate the pattern of injury.

\section{Subjects and Methods}

This prospective study was conducted in department of Burns, Plastic and Maxillofacial Surgery, Safdarjung Hospital, New Delhi over a period of one year. 


\section{Inclusion Criteria}

1. All patients reporting to safdarjung hospital plastic surgery department due to acute electric burns were included in the study.

\section{Exclusion Criteria}

1 Patients who presented more than 4 days after electric burns were excluded from early flap cover study.

All patients were evaluated clinically with detailed history, and physical examination. History specifically included.

1. The type of the current: (high voltage/low voltage)

2. Any treatment taken outside: Details of treatment:

3. Type of burn (contact/flash/arc)

\section{The physical examination will specifically included}

1. Area of contact: entry point and exit point:

2. Extent of burns [TBSA]

3. Associated injuries

[neurological/musculoskeletal/cardiac]

The patients were followed throughout their hospital stay to assess the final outcome.

Imaging investigations like CT scan, MRI were done as and when required.

Informed consent was taken from all the patients.

Statistical analysis was done using data analysis software with the help of the statistician.

\section{Result}

Our study was done from first January 2011 to thirty first December 2011 in safdarjung hospital. Total number of patients treated for electrical burns during this period is 438 . Total number of patients treated for burns of all kinds during the same period is 5569. This represents an incidence of $7.86 \%$ electrical related burns.

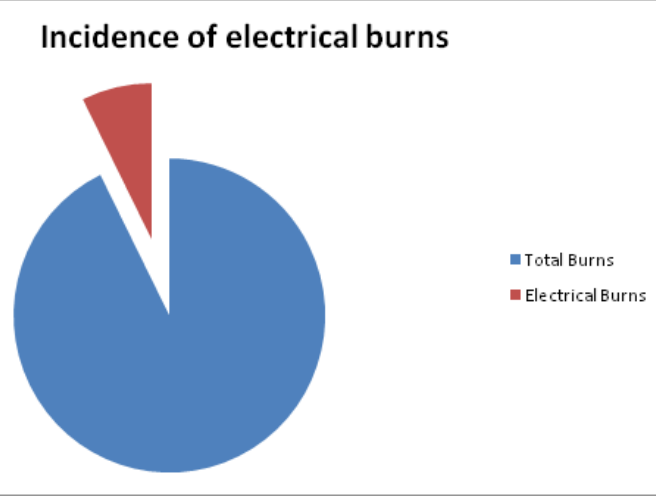

Figure 1: Incidence of Electrical burns

Age

The age of the patients who suffered electric burns ranged from five months to eighty years. The age groups maximum affected are sixteen years to thirty years.

\begin{tabular}{|l|l|l|}
\hline Table 1: Age distribution of the patients \\
\hline Age Group & No. Of Patients & Percentage \\
\hline $0-5$ & 32 & $7.3 \%$ \\
\hline $6-10$ & 38 & $8.7 \%$ \\
\hline $11-15$ & 40 & $9.1 \%$ \\
\hline $16-20$ & 70 & $16 \%$ \\
\hline
\end{tabular}

\begin{tabular}{|l|l|l|}
\hline $21-25$ & 85 & $19.4 \%$ \\
\hline $26-30$ & 50 & $11.4 \%$ \\
\hline $31-35$ & 35 & $8 \%$ \\
\hline $36-40$ & 27 & $6.2 \%$ \\
\hline $41-45$ & 13 & $3 \%$ \\
\hline $46-50$ & 22 & $5 \%$ \\
\hline $51-55$ & 10 & $2.3 \%$ \\
\hline $56-60$ & 7 & $1.6 \%$ \\
\hline $61-65$ & 3 & $0.7 \%$ \\
\hline $66-70$ & 4 & $0.9 \%$ \\
\hline $71-75$ & 1 & $0.2 \%$ \\
\hline $76-80$ & 1 & $0.2 \%$ \\
\hline
\end{tabular}

Electric burns were more common from childhood up to forty years age group. After forty years of age the incidence of electrical burns started declining.

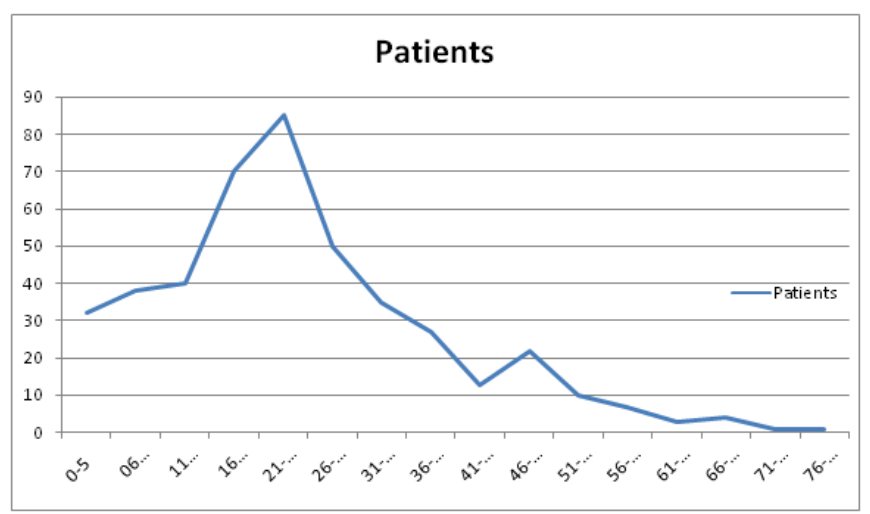

Figure 2: Age distribution among the total patients

The above figure indicated that maximum peak was appreciated in the twenty one to twenty five age groups.

\section{$\underline{\operatorname{Sex}}$}

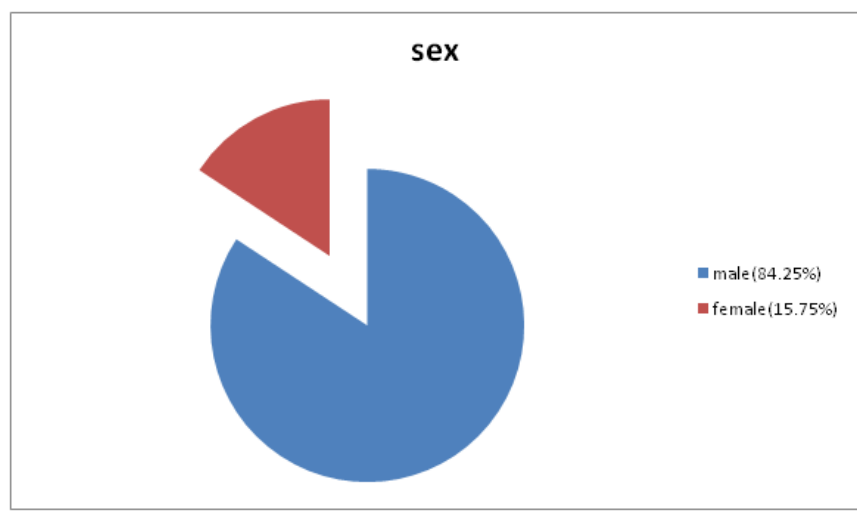

Figure 3: Sex ratio of the patients

In the present study, there was a male preponderance in electric burns. Out of total 438 patients males were 369 and females were 69 . This represented that $84.25 \%$ of the patients were male.

\section{Children}

Children were taken, as under the age of twelve. There were total of 81 cases. This represented that children constituted $18.5 \%$ of all patients injured by electrical burns. After the young age group, children were the most commonly injured. 


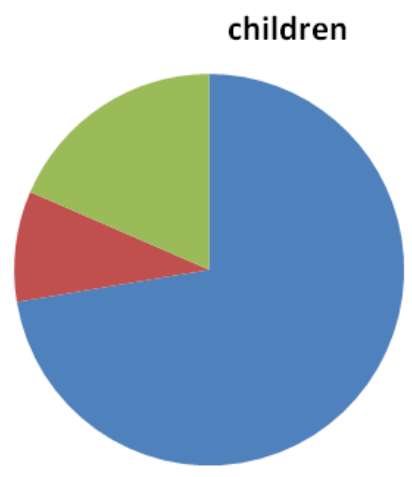

- Male Adults

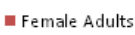

In Childrens $<12$

Figure 4: Children ratio of total burn cases

Table 2: Seasonal Variation in Burn Cases

\begin{tabular}{|l|l|}
\hline Month & No of patients \\
\hline January & 19 \\
\hline February & 29 \\
\hline March & 21 \\
\hline April & 37 \\
\hline May & 29 \\
\hline June & 56 \\
\hline July & 49 \\
\hline August & 59 \\
\hline September & 49 \\
\hline October & 39 \\
\hline November & 31 \\
\hline Dec & 20 \\
\hline
\end{tabular}

In the present study, the above table shown a definite seasonal variation was observed with the highest number of patients in June to September months (48.6\%). Relatively lower numbers of patients were observed in December to march months (20.3\%).

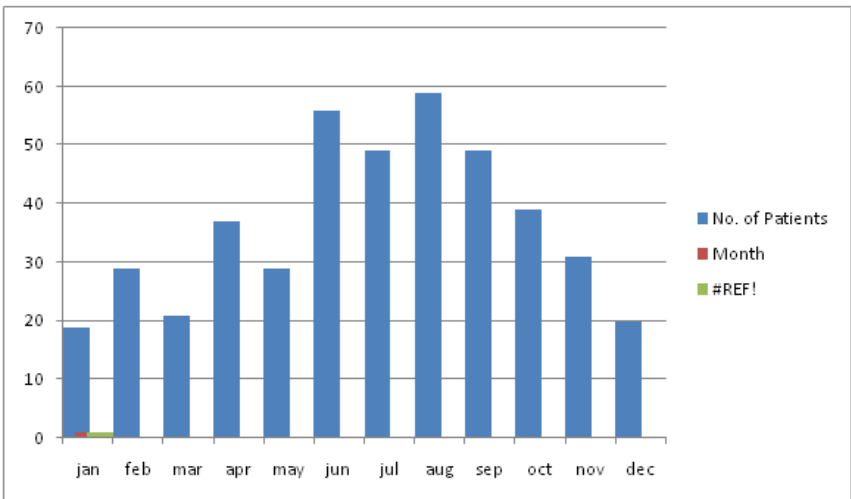

Figure 5: Seasonal incidence in Burn cases

\section{Electricity voltage}

As per standard medical literature high voltage was taken as more than 1000volts and low voltage as less than 1000volts. In our study we found that there were 312 high voltage injuries and 126 low voltage injuries.

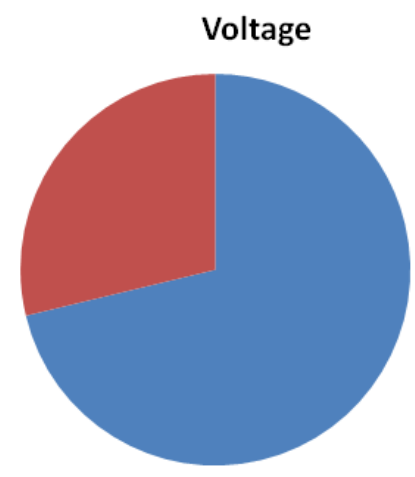

Eigh

Figure 6: Voltage pattern in Burn cases

\section{Type of electric injury}

Though electric injuries can cause direct contact, flash, arc and flame injury due to clothes etc catching fire, in our study period we did not encounter arc and flame injuries in electric burn patients.

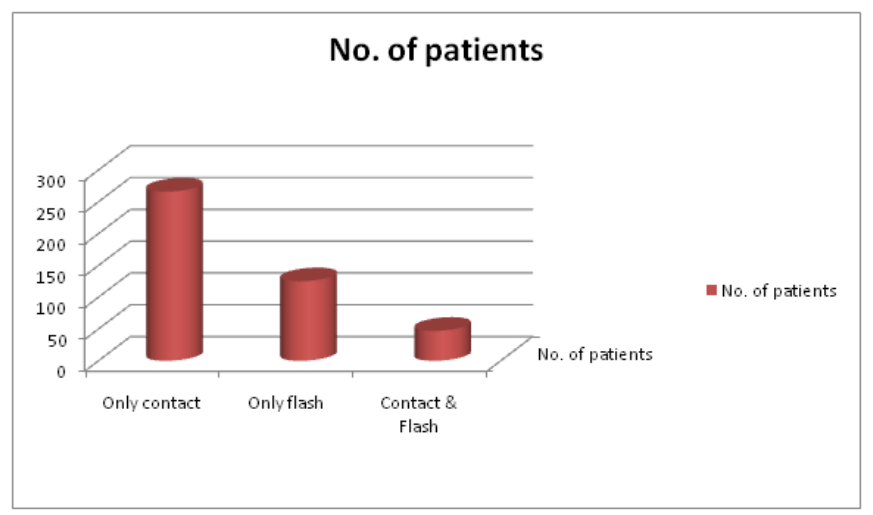

\section{Figure 7: Type of Electrical injury}

In our study majority of the patients (266) had direct contact burns. 125 patients had only flash burns and 47 patients had both contact and flash burns.

Table 3: Cause of electric injury

\begin{tabular}{|l|l|}
\hline Cause of injury & No of patients \\
\hline Agriculture related & 186 \\
\hline Domestic(within home) & 114 \\
\hline occupational & 82 \\
\hline Roof of home(terrace) & 36 \\
\hline Kite flying & 7 \\
\hline Transformer near house & 5 \\
\hline Tapping electricity & 4 \\
\hline Sitting on train top & 2 \\
\hline Sitting on vehicle top & 2 \\
\hline
\end{tabular}

In our study, we found that the major cause of electric injuries was while doing agriculture related work(rural areas) in fields etc. domestic injuries that is injuries within the home majorly being low voltage injuries was the next common occupational injuries included injuries while doing occupation like electric company workers, electricians, people working in cable industry and industrial injuries. Electric injuries occurring to patients while working or playing on the roof of house were majorly high voltage injuries because of low lying high voltage lines or high voltage lines passing very near to house. 4 patients were 
injured when trying to tap electricity illegally from electric lines. 2 were injured while sitting on top of trains. 2 more were injured when they were sitting on top of an open vehicle(tractor) and when the vehicle accidentally came in contact with electric lines running above the road.

\begin{tabular}{|l|l|}
\hline Table 4: Type of associated injuries \\
\hline Head injury & 6 \\
\hline Spinal injury & 2 \\
\hline Atrial fibrillation & 2 \\
\hline Blunt injury abdomen & 1 \\
\hline Clavicle fracture & 3 \\
\hline Humerus fracture & 1 \\
\hline Femur fracture & 1 \\
\hline
\end{tabular}

Out of 6 head injuries, 2 had no abnormal findings on ct scan head, while 2 had intra-cerebral bleed, 1 had extra dural haemorrhage, 1 had sub arachnoid haemorrhage. Out of the 2 spinal injury patients whilt 1 had c5-c6 fracture dislocation the other patient had $\mathrm{t} 7$ stable vertebrae burst fracture.

Renal failure was present in 5 patients during this study period.

\section{Discussion}

The incidence of electrical burn injuries seems to be increasing in the past few years in developing countries like India. The morbidity and mortality of electrical burn injuries is very high. The present study attempts to find the epidemiology of electrical burns.

Our study was done from first January 2011 to thirty first December 2011 in safdarjung hospital. Total number of patients treated for electrical burns during this period is 438 . Total number of patients treated for burns of all types during the same period is 5569. This represents an incidence of $7.86 \%$ electrical related burns.

This study reveals that the highest incidence of electrical burn injuries is in the 21 to 30 years age group. Of all the patients studied, nearly $31 \%$ patients were between 21 to 30 years. $41 \%$ patients were in the age group 0 to 20 years. In comparison with studies done in the last 2 decades, there is a visible shift in the age group of patients to the younger age group. Hussmann ${ }^{[4]}$ reported that $26 \%$ patients were in the age group of 20 to 30 years and $36.8 \%$ between 0 and 20 years. In the $1990 \mathrm{~s}$, Robson ${ }^{[6]}$ reported a $44.5 \%$ incidence of electrical burns in the age group of 20 to 30 years while only $15.6 \%$ patients were between 0 and 20 years. Thus, it is evident that the majority of patients reporting for treatment now are younger. This scenario seems to be unique to electrical burn injuries. Trends at our institute suggest that for a long time, the most common patients presenting with thermal burn injuries are young women in their second and third decades of life. However, the shift of age group in electrical burn injuries is clearly seen. It could be possible that this shift is because of increased household injuries. In developing countries, occupational injuries used to be the most common cause of electrical burns. In recent times, especially in a country like India, the economic surge has made electricity available even in remote interiors but people lack knowledge for handling electricity safely.

Unfortunately, education and awareness have not kept pace with economic growth, and hence, these demographic changes are seen. Although electricity is now available even in the remote areas, no specific attempts to educate people regarding the dangers of electrical burn injuries and methods of prevention have been made.

In our study, 369 of the 438 patients were male. This represents that an overwhelming $84.25 \%$ were male. Probably, this is because of increased outdoor activities, greater participation in agriculture, occupational exposure, more contact with electrical appliances when compared to females. Increased incidence of electrical injuries in males has been reported in various other studies like Robson et al. ${ }^{[9]}$

Children for this study were taken as under the age of twelve. There were total of 81 cases constituting $18.5 \%$ of all patients injured by electrical burns. Majority of them were caused within the home premises (domestic). Children received high voltage injuries while playing on roofs of houses which were near low lying high tension lines or by going near transformers which were near their homes.

A definite seasonal variation was observed with the highest number of patients in june to September months (48.6\%). Relatively lower numbers of patients were observed in December to march months $(20.3 \%)$. This high incidence in June to September months could be due to monsoon season during that period resulting in moist conditions leading to electrical burns and also could be due to agriculture harvesting season.

In our study we found that there were 312 high voltage injuries and 126 low voltage injuries. Majority of these low voltage injuries were domestic 240 volt injuries. These numbers were also consistent with Robson et al [9] where it was noticed that high voltage injuries was more common than low voltage injuries.

In our study regarding the type of electric burn (majority) 266 of the patients had contact burns. 125 patients had only flash burns and 47 patients had both contact and flash burns. This is in contrast to Robson et al where flash burns were more than contact burns.

In our study, we found that the major cause of electric injuries was while doing agriculture related work in fields etc (rural areas).this could be due to illiteracy, lack of information in agriculture related workers, families in rural areas. A domestic injury that is injuries within the home majorly being low voltage injuries was the next common. 36 cases of electric injuries were noted when patients were present on their roof tops (terrace). Electric injuries occurring to patients while working or playing on the roof of house were majorly high voltage injuries because of low lying high voltage lines or high voltage lines passing very near to houses. 4 patients were injured when trying to tap electricity illegally from electric lines. Leibovic et $\mathrm{al}^{[7]}$ reported that $10 \%$ of high-voltage injuries in their study were because of illegal theft of copper wires.

7 patients received electric burns while kite flying. Naked live high-tension wires that were dangerously close to the residential areas were responsible. Similar findings have been reported by Robson et al. ${ }^{[9]} 2$ were injured while sitting on top of trains. 2 more were injured when they were sitting on top of an open vehicle (tractor) and when the vehicle accidentally came in contact with electric lines running 
above the road.

Improperly insulated wires, poorly placed and managed electrical switches, presence of preschool children at home, overcrowding at home, poor socioeconomic status, and illegal electrical connections were found to be the contributing factors for domestic injuries. In contrast to our study, earlier reports suggest that the workplace had been the most common place of electrical injuries. Holliman et $\mathrm{al}^{[12]}$ had reported that most injuries occurred at places of work. Hussmann et al had reported a $72 \%$ incidence of workrelated injuries.3 Jiang et al., ${ }^{[1]}$ observed that $52 \%$ of injuries occurred at work places, whereas only $20.8 \%$ of injuries occurred at home. Similarly, Leibovic et $\mathrm{al}^{[7]}$ reported a $34 \%$ incidence at workplace and only $19 \%$ at home.

\section{Conclusion}

The current preventive programs are essentially found wanting. It is apparent that lack of information is the major limiting factor in these injuries. We believe that use of both passive and active measures is required to achieve the goal. The government, schools, manufacturers, local authorities, and general public all need to play their role effectively to arrest this increase in the rate of electrical burn injuries. Were commend that preventive programs should strive to impart adequate information especially at the school going age; local governments need to impart personalized education to the rural population regarding electrical burn injuries; simple passive measures like making use of local language and dialect for manufacturers' instructions and signboards; and the print and electronic media should be used effectively to impart necessary information.

\section{Acknowledgment}

The author would like to thank Department of Burns, Plastic and Maxillofacial Surgery, Safdarjung Hospital, New Delhi for providing all the facilities to carry out this research work.

\section{References}

1. Price T, Cooper MA. Electrical and Lighting Injuries. In: Marx J, Hockberger R, Walls R. Rosen's Emergency Medicine. Vol 3. 5th ed. Mosby; 2002:2010-2020.

2. Ferreiro I, Melendez J, Regalado J, Bejar FJ, Gabilondo FJ. Factors influencing the sequelae of high tension electrical injuries. Burns. Nov 1998;24(7):649-53. [Medline].

3. Luce E.A. Electrical injuries. In: J.G. McCarthy (Ed.), 'Plastic Surgery', 814-830, WB Saunders Company.

4. Brain E Benson, MD et al. Article on burns, Electrical injury, emedicine.

5. James M. Shaw and Martin et al. Electrical injuries total burn care,401-406.

6. Lee RC. Injury by electrical forces: pathophysiology, and manifestation. Curr. Probl. Surg. Sep.1997; 34(9): 677-764.

7. Leibovici D. Shemer J. Shapira SC, Electrical injuries: Current concepts. Nov.1995; 26(9): 623-7.

8. Skoog T. Electrical injuries. J. Trauma 1970; 10: 816-30.

9. Robson Mc Morphy RC. Heggers JP. A new explanation for the progressive tissue loss in electrical injury. PRS 1984; 73 : 431-7.

10. Hussmann J, Kucan JO, Russell RC, Bradley T, Zamboni WA. Electrical injuries--morbidity, outcome and treatment rationale. Burns. Nov 1995;21(7):530-5. [Medline].

11. Jiang MJ, Li Z, Xie WG. Epidemiological investigation on 2133 hospitalized patients with electrical burns. Zhonguhua Shao Shang ZA Zhi 2017;33(12):732-7.

12. Holliman CJ et al. Early surgical decompression in themanagement of electrical injuries. Am. J. Surg., 144 : 733-739, 1982.

Copyright: (C) the author(s), 2019. It is an open-access article distributed under the terms of the Creative Commons Attribution License (CC BY 4.0), which permits authors to retain ownership of the copyright for their content, and allow anyone to download, reuse, reprint, modify, distribute and/or copy the content as long as the original authors and source are cited.

How to cite this article: Pratap D, Sarabahi S, Tiwari VK, Annapareddy SNR. Clinical To Study the Incidence of Electrical Contact Burns and To Evaluate the Pattern of Injury in a Tertiary Burn Care Centre. Acad. J Surg. 2019;2(2):40-44.

DOI: dx.doi.org/10.21276/ajs.2019.2.2.11

Source of Support: Nil, Conflict of Interest: None declared. 